\title{
THE ENERGY POTENTIAL OF BLACK SEA IN ROMANIAN SEASIDE AREA
}

\author{
Valentina Jalan ${ }^{1}$, Dumitru Dinu ${ }^{1}$ \& Raluca Radulescu ${ }^{2,3}$ \\ ${ }^{1}$ Constanta Maritime University, Doctoral School of Electro-Mechanics Engineering, 104 Mircea cel Batran Street, \\ 900663, Constanta, Romania, valentinapoenaru17@gmail.com \\ ${ }^{2}$ Politehnica Bucharest, Doctoral School of Energy, Faculty of Energy, Romania, raluca.radulescu@icloud.com \\ ${ }^{3}$ National Institute for Research and Development on Marine Geology and Geoecology - GeoEcoMar, 304 Mamaia \\ Blv., 900581, Constanta Romania, raluca.radulescu@geoecomar.ro
}

\begin{abstract}
The Black Sea is considered a relatively calm sea, the optimal choice for the capture process is influenced by the wave regime and its peculiarities. This sea is characterized by winds that blow towards land with greater intensity in January causing the sea to be more agitated and with less power in May, June and July, when the sea was the calmest of the year. It should be noted that the frequency of strong winds is $38 \%$, and of those of low speed of $1 \mathrm{~m} / \mathrm{s}$ of only $1.5 \%$. For the collection of oceanographic and meteorological information, data provided by the Gloria platform located in front of Romania's coast were is used, as well as records from the three offshore buoys anchored in the Romanian seaside area and which are part of the EMSO EUXINUS research infrastructure managed by National Institute for Research and Development on Marine Geology and Geoecology - GeoEcoMar. In addition, free data such as those provided by the site of the research institute Grigore Antipa were easily accessed. Presently there are three fixed platforms in the Black Sea. Wave energy is underexploited, both worldwide and in the Black Sea. The potential of this type of energy is huge, and the environmental impact is low compared to other renewable energy technologies.
\end{abstract}

Key words: Black Sea, energy potential, Romanian seaside, climate.

\section{INTRODUCTION}

Waves are a form of hydraulic energy present in nature along with the flow energy of rivers and streams, sea currents or periodic oscillations of the tides. This form of energy results from the combined action of winds + gravity + surface tension at the surface of the sea.

The energy contained in the wave is an indirect form of solar energy resulting from the heating of large water masses of the planetary ocean, but also of the surface of the land, thus resulting in winds. These winds thus formed blow over large expanses of water and transmit some of their energy to them.

Wave energy has the following advantages:

- Renewable and inexhaustible energy;

- Huge energy potence;

- Clean energy;

- It is present in two-thirds of the surface of water covering the globe;

- The areas in which the means of extracting this type of energy may be arranged are areas not used by man to inhabit or exploit the land (except for waterways).

Among the disadvantages are the following:

- It varies continuously depending on the characteristics of the wind, season and location;
- High operating price compared to other forms of energy;

- Visual and physical impact on marine habitat;

- Capture devices may have certain leakage of liquids toxic to the marine environment;

- Merchant ships may encounter navigational difficulties.

\section{THE CLIMATE OF THE BLACK SEA IN THE ROMANIAN SEASIDE AREA}

Marine waters are in constant motion as a result of the complex action of external factors (wind, planetary gravitational force, atmospheric pressure, earth movement), internal (differences in density and temperature) and dynamics of the Earth's crust (earthquakes, volcanic eruptions). The energy required to induce movement in ocean masses is generated through the air-ocean interface [1].

\subsection{The currents regulation in the Romanian seaside area:}

In this area is recognized a main current called the Main Circumbasinal Current (CPC) or border. This 
current has a geostrophic character, which develops in the form of a wide current of about $50 \mathrm{~km}$, up to depths of $-150 \mathrm{~m}$, moving with average speeds of $15-20 \mathrm{~cm} / \mathrm{s}$, and with an average annual flow of $6 \mathrm{~Sv}$, which fluctuates between $8 \mathrm{~Sv}$ in spring and $4 \mathrm{~Sv}$ in autumn. CPC is distinguished at sea surface level by temperatures of 2 to $3^{\circ} \mathrm{C}$ and salinity values $1-2 \%$ higher than shore waters. The entire spatial and temporal structure of the Main Current is determined by the geostrophic, meandering and circular processes, being discontinuous in time and very variable in space [2].

In addition to the CPC, there are two additional currents that unfold inside the main one in reverse direction, one in the eastern compartment and one in the western (Figure 6). The two currents have increasingly lower speeds and flows towards their center.

On the Romanian coast, the linear displacement of the CPC is disturbed by the irregular appearance of the shoreline (heads, rocks, port constructions). Leading to formation of, three main anticycloneal current cells, namely: Sulina Sud, Sacalin - Portiţa, Constanţa Sud.

The data regarding the current in the Romanian seaside area are processed starting with June 2013 by GeoEcoMar specialists, using three EMSO-EUXINUS offshore buoys with early monitoring and alerting system in case of exceptional events (Figure 1).

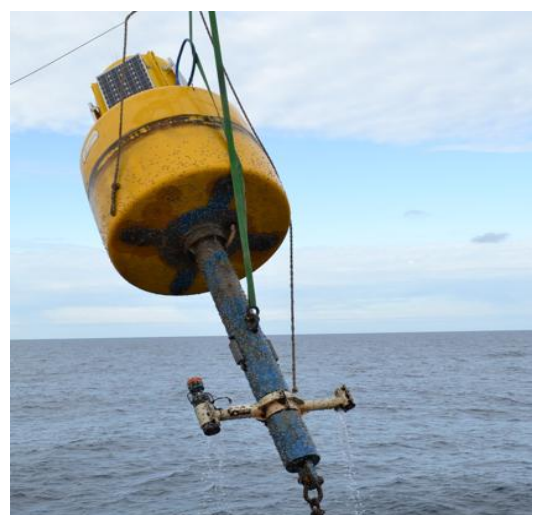

Figure 1 EMSO-EUXINUS offshore buoy

The three offshore buoys are positioned about 50 $\mathrm{Nm}$ from the shore having a distance between them 30 $\mathrm{Nm}$ and are installed at a depth of about $80 \mathrm{~m}$ as can be seen in Figure 2.

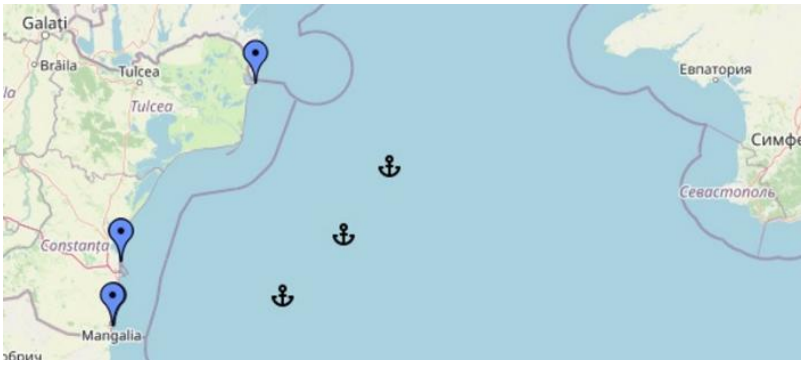

Figure 2 Locations of EMSO EUXINUS offshore buoys (Romanian seaside)

The EMSO-EUXINUS infrastructure, through the components that serve it is actively involved in the effort to study the planet's ocean by participating since 2013 in EMSO ERIC, the pan-European research infrastructure that coordinates research facilities and monitoring the marine aquatic environment in Europe's seas and oceans. EMSO, which became EMSO ERIC in 2016 consists of a network of observatories that provide coherent data sets containing information on surface and shallow waters (collected through the water column) and information on the ocean floor with aspects their geological, geophysical, biochemical and ecological. The research area is extensive - from the Atlantic Ocean to the Mediterranean Sea and from the Marmara Sea to the Black Sea, and this allows a wide range of studies of various environments. The collected data is transmitted to land stations via telecommunication cables or satellite connections [3].

According to the data provided by the three offshore buoys EUXRo01, EUXRo02 and EUXRo03, the current in the area where they are located has a tendency to rotate clockwise over the course of a day around each individual offshore buoy but in a cyclonic sense from one buoy to another. The circulation of the current in the coastal marine aquatory area, in the waters where the buoys are installed, is determined by the wind/waves, and at the outer edge (towards the open sea) it is influenced by the Main Current of the Black Sea. Thus, several small, anticyclonic "eddy" cells emerge here, which penetrate discontinuously into the aquatory shelf [4].

The data provided by the GeoEcoMar institute, provide the direction and amplitude of the current for the period 2013-2020 from hour-to-hour basis over the course of a year. So, for each year there are about 8500 records of this data. The information was processed with the help of a special program that rendered the current on a graph in the form of a rose built so as to keep the direction of the current to the north and the cardinal points, having as concentric circles the amplitude of the current in ascending order from the weakest to the most intense for each point represented.

Thus, we can say that the theory is confirmed after the construction of the graphs with parameters as 
recorded by the three buoys (Figure $3 \mathrm{a}, \mathrm{b}$ and c) and collected data processed over a period of 8 years (20132020). It is worth mentioning that certain data are missing due to the maintenance brushes of the offshore buoys, unfavorable weather factors or certain technical problems.

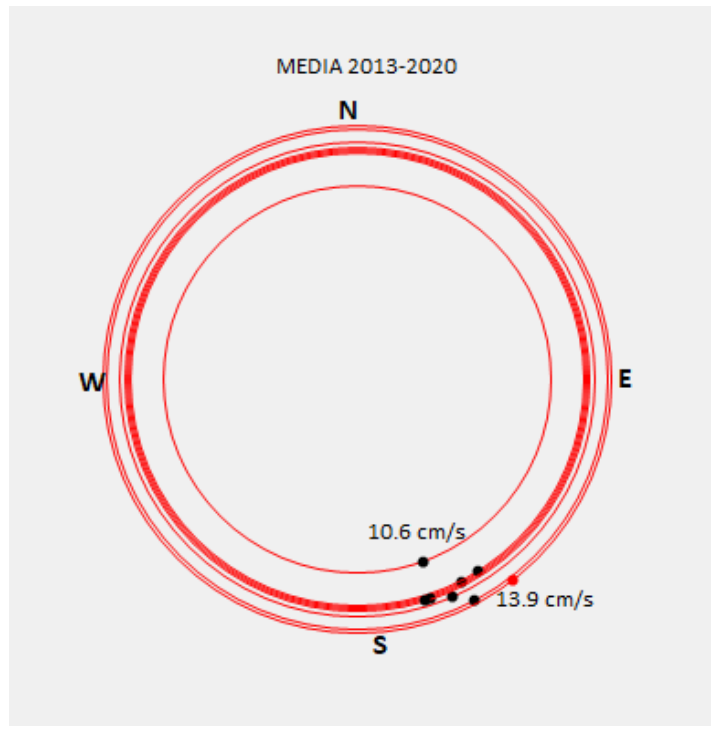

Figure 3 a) Current direction and average water amplitude in the period 2013-2020 (EUXRo01)

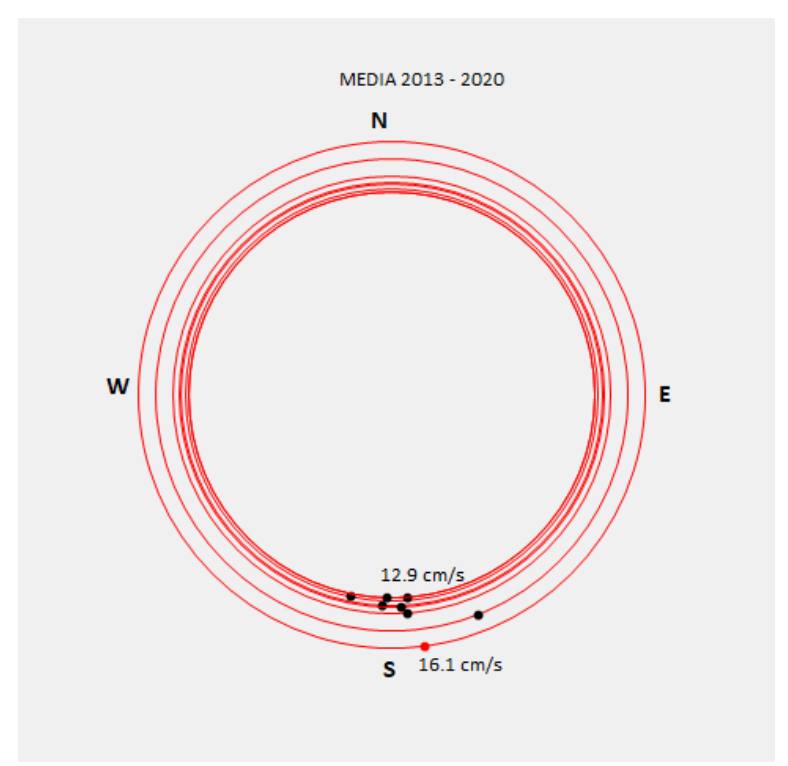

Figure $3 \mathrm{~b}$ ) Current direction and average water amplitude in the period 2013-2020 (EUXRo02)

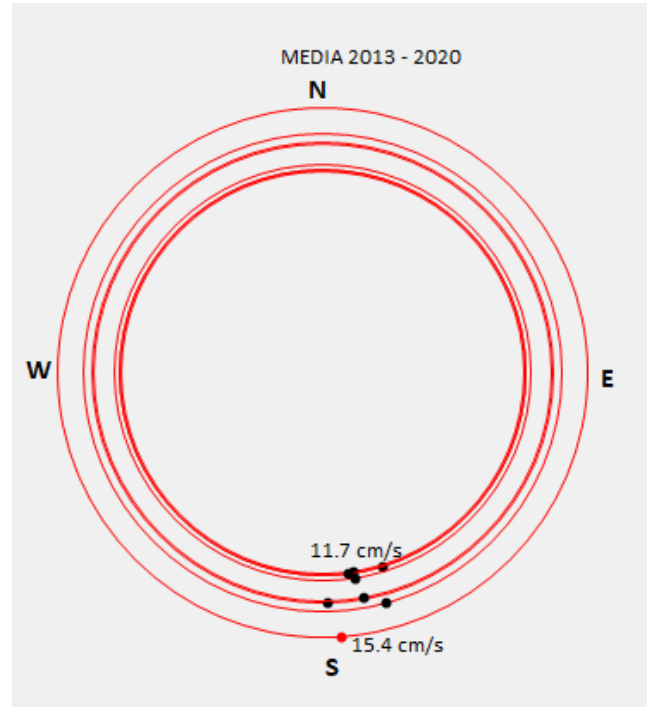

Figure 3 b) Current direction and average water amplitude in the period 2013-2020 (EUXRo03)

Analyzing the data obtained from the offshore buoys we notice that the average amplitude of the current registers a maximum value in April-May and sometimes with extension towards June and a minimum around February-March and OctoberNovember but sometimes reaching until December and isolated in January (figures 4, 5 and 6).

The current has a higher average amplitude the more we move to the south, so a possible use of it to capture energy would be justified south of the Port of Constanta, given the constructions related to the port of Constanta and the navigation routes for the entrance to the port. 


\section{EUXRo01}

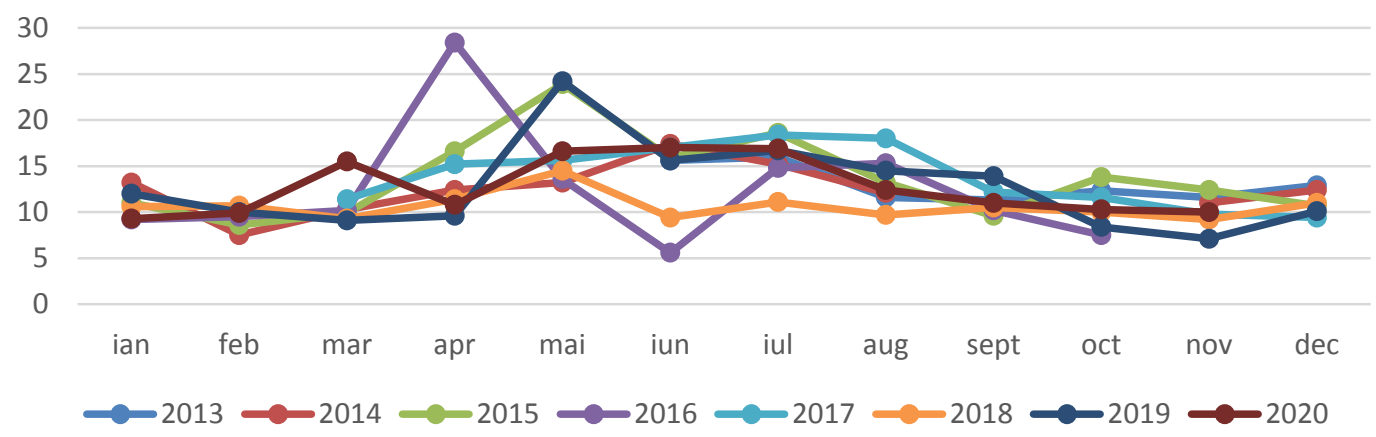

Figure 4 Average current amplitude in the period 2013-2020 for EUXRo01

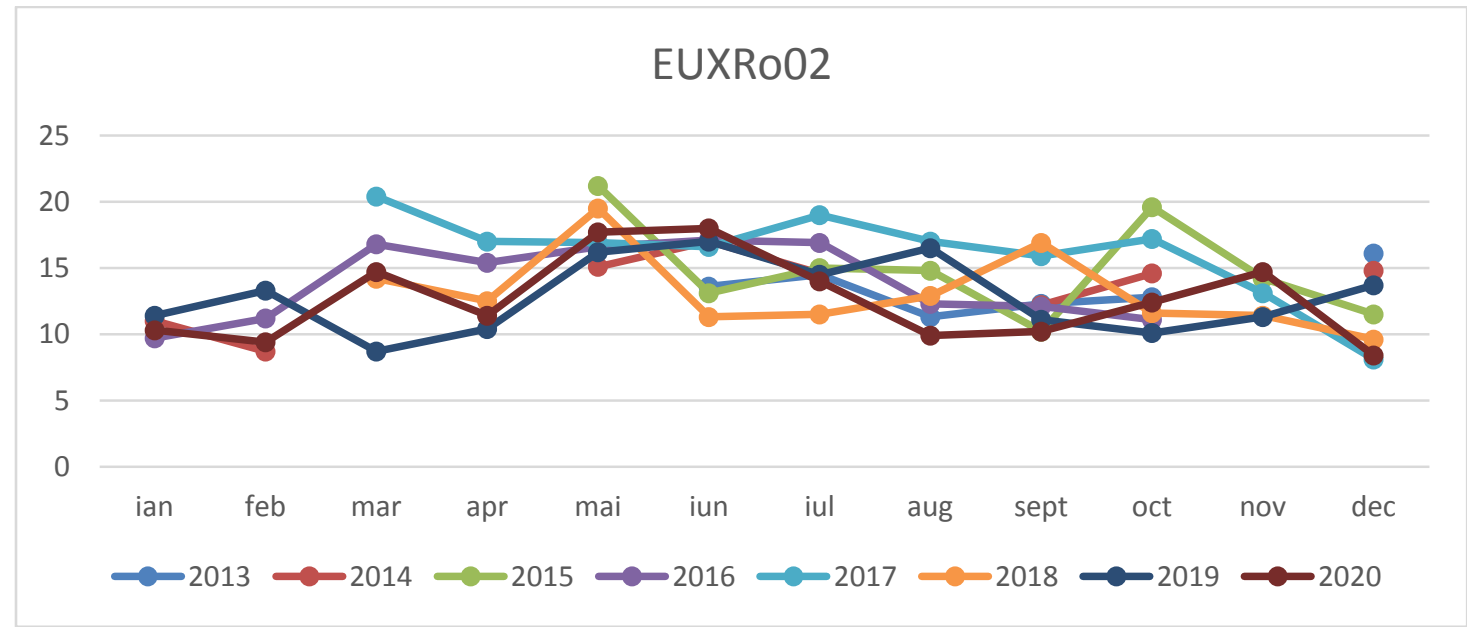

Figure 5 Average current amplitude in the period 2013-2020 for EUXRo02

\section{EUXRo03}

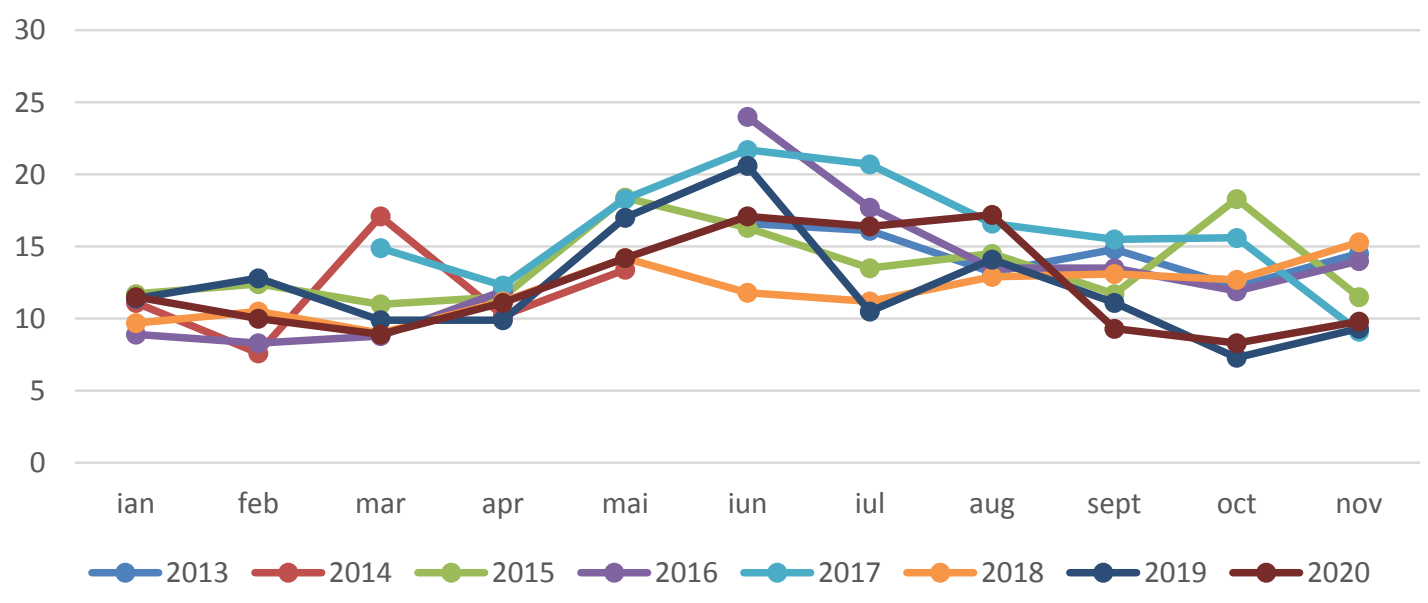

Figure 6 Average current amplitude in the period 2013-2020 for EUXRo02 


\subsection{The waveregim in the Romanian seaside area:}

The movements of the air masses continuously influence the formation of the waves being a primary factor of their genesis. The energy of these air masses is transferred to the water on a certain surface, called fetch, and depending on this surface of action, the waves can increase until the sea is no longer influenced by the action of the air masses (the wind), being fully developed as in the case of storms. Of course, the duration of action of the wind is directly proportional to the size and energy of the wave, time being another factor that contributes to the generation of the waves.

Wind waves are the most widespread, and even its action thousands of kilometers from a certain geographical area is enough to create waves. The displacement of the air mass upon contact with the water layer produces the phenomenon of friction, part of the energy of the air is transferred to the water, with the effect of amplifying the wave [1].

According to GeoEcoMar on the Romanian seaside, the measured wave data, are few and have low accuracy, due to the visual estimation of the height and direction. Recordings are interrupted during extreme events (storms, etc.) due to low visibility, in this way the most important data for coastal zone dynamics are missing [5]. Starting with 2014, continues wave data are recorded by the EMSO EUXINUS Mangalia Coastal Gauge at 5 minute interval.

Currently, a wave height measuring station is available in Mangalia near the offshore at 15 meters water depth in front of Mangalia city. This position is too fresh offshore to conclude the wave regime in the coastal area, and the information from a single station is not enough for entire Romanian waters, but useful for southern part of Romanian coast as case studies.

The wave information obtained with the Ivanov perspectometer from the Genoese Lighthouse in Constanta requires a better appreciation of the apparatus from the one who uses it, and the errors due to the orientation of the coast are willful because the wave has a tendency to orient parallel to the coast.

However, if we were to consult free sources such as [6] we can get some information about the wave in the area of interest, the value of the raw energy potential of the waves near the Romanian seaside is relatively low. The studies and researches made in the country prove that, on each linear meter of maritime front arranged, approximately $40 \quad 000-50 \quad 000 \mathrm{kWh} /$ year or $8-10$ $\mathrm{TWh} /$ year can be obtained, in the case of installation of a single continuous string of capture systems with an efficiency equal to $100 \%$. For a total efficiency of only $30 \%$, the value of the possible energy potential would be around 2.4 to $3 \mathrm{TWh} /$ year, which shows that the black sea waves would be cost-effective if its mechanical force generation potential is used for energy generation purposes [7].
Thus, according to an analysis made by [8], using the values of the wave offered by the Gloria Platform located off the Romanian coast, it can be concluded that an energy with values between $3-4 \mathrm{~kW} / \mathrm{m}$ is available in the western part of the Black Sea in the Romanian seaside area (figure 7).
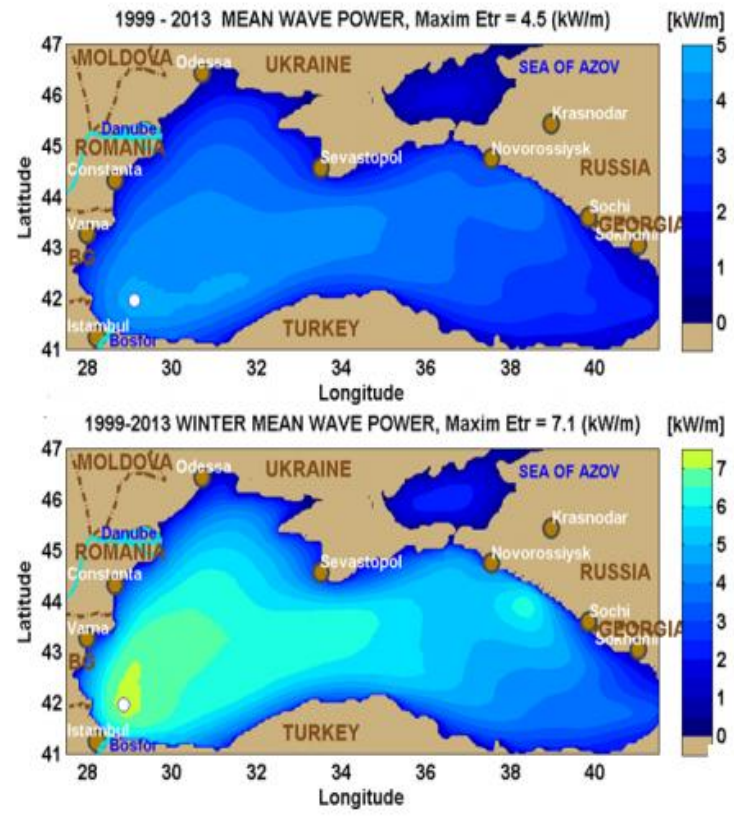

Figure 7 The wave power resulting from the SWAN simulation for 1999-2013 [8]

\subsection{Wind regulation in the Romanian seaside area:}

Due to the varied configuration of the shore, the winds form different wave fields in the Jibrieni - Sfântu Gheorghe, Sfântu Gheorghe - Chituc and Cape Midia Vama Veche portions, and under the action of the SW winds, the area between Sfântu Gheorghe and Portiţa becomes a difficult area while the rest of the Romanian coast (due to the general orientation of the NS shore) is protected from the action of the wind. Under the action of the north winds the whole coastline in the western part of the Black Sea becomes very agitated, except for The Portiţa Bath [9].

Although the wind direction is very variable over the course of a year, the general north-south orientation of the coastline and the bathymetric curves, as well as the small distance from the observation point to the shore, strongly distorts the distribution of the directions of wave propagation. The asymmetry of their distribution in the shallow area is, on one hand due to the limitation of the fetches for the winds in the western sector and, on the other hand, to the refractive effect that makes the wave ridges parallel to the shoreline. Thus, $92 \%$ of the observed waves propagate from the NE-E-SE sector [10]. 
Thus, analyzing the data provided by the EUXRo01 offshore buoy we notice that the wind direction in this area is maintained in the SE dial as shown by Figure 7.

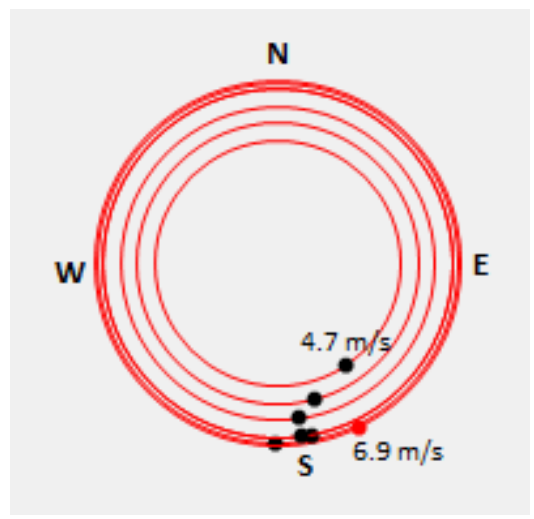

Figure 7 Wind in anchorage position of the EUXRo01 offshore buoy for the period 2013-2020

The local wind, such as the breezes, the mountainous circulation of the valleys, around the Black Sea, have a remarkable impact on the atmospheric condition in the coastal area [11]. The speed of the breezes varies between $1-3 \mathrm{~m} / \mathrm{s}$ along the shore, and offshore it is $4-6 \mathrm{~m} / \mathrm{s}$.

\section{CONCLUSIONS}

The hydrodynamic processes that take place in the marine environment are generated by the complex phenomena of the interactions between the sea and the atmosphere.

The exchanges of kinetic energy between the two environments cause the formation of sea currents and waves. The availability of wave data measured over a long time period in the Romanian offshore northern part is non-existent.

Another important issue that should be taken into account is that the dynamics of the coastal processes in the western side of the Black Sea is usually very high and the marine energy farms can play also an active role in the coastal protection.

Thus, although a power of about $4 \mathrm{~kW} / \mathrm{m}$ would be available offshore, converters can be built that would operate at a lower wave power ( $1 \mathrm{MW}-2 \mathrm{MW})$, specific to the area in the immediate vicinity of the shore (Constanta Port area or further south of the coast).

\section{REFERENCES}

[1] Boșneagu, R., 2019, Oceanography for seafarers, Ex Ponto Publishing House, Constanța, 2019;
[2] Vespremeanu-Stroe, A., 2004, Sediment transport along the shore and wave regime on the Danube Delta coast. Studies and researches of oceanographycostal, 1 , 67-82;

[3] http://euxinus.eu

[4] Vespremeanu, E., 2005, Geografia Mării Negre. University Publishing House, Bucharest.

[5] Dan, S., Stănică, A., F.A., 2017, Comparative Analysis of the wave data measured and calculated in the Romanian seaside area, J.Geo-Eco-Marina

[6] https://www.ngdc.noaa.gov/

7] Spânu, I., 2012, The XII-th National Multidisciplinary Conference - with international participation, Sebeș.

[8] Rusu., L., 2015, Assessment of the Wave Energy in the Black Sea Based on a 15-Year Hindcast with Data Assimilation, Energies 2015, 8, 10370-10388; doi:10.3390/en80910370.

[9] Bumblebee C., Emanoil G., 1963 , Contributions to the study of the Black Sea agitation on the RPR coast. St.Hydrology, Bucharest, 4: 89-160.

[10] Mihailov, M. E., Buga, L., Malciu, V.,Stefan, S.,Tomescu-Chivu, M., I., Diaconu, V.,Ganea, G.,Dumitrache, L., Matei, S., 2013, Wave characteristics in the Romanian nearshore waters, J.Water Resources. Forest, Marine and Ocean Ecosystems Conference Proceedings "13th International Multidisciplinary Scientific Geoconference SGEM 2013", pg. 879-886.

[11] Anton I.A., Panaitesacu M., Panaitescu F.V., Ghita S., 2019, Impact of beach protection systems on coastal ecosystems, E3S Web of Conferences 85, 07011 (2019) 